\title{
Evaluation of Nile Delta-Mediterranean Sea Conjunction Using GPS, Satellite-Based Gravity and Altimetry Datasets
}

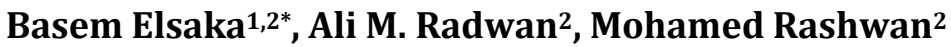 \\ ${ }^{1}$ Institute of Geodesy and Geoinformation, University of Bonn, Bonn, Germany \\ ${ }^{2}$ National Research Institute of Astronomy and Geophysics (NRIAG), Helwan, Cairo, Egypt \\ Email: ^elsaka@geod.uni-bonn.de
}

How to cite this paper: Elsaka, B., Radwan, A. M., \& Rashwan, M. (2020). Evaluation of Nile Delta-Mediterranean Sea Conjunction Using GPS, Satellite-Based Gravity and Altimetry Datasets. Journal of Geoscience and Environment Protection, 8, 33-46. https://doi.org/10.4236/gep.2020.82003

Received: January 1, 2020

Accepted: February 2, 2020

Published: February 5, 2020

Copyright $\odot 2020$ by author(s) and Scientific Research Publishing Inc. This work is licensed under the Creative Commons Attribution-NonCommercial International License (CC BY-NC 4.0). http://creativecommons.org/licenses/by-nc/4.0/

\section{Abstract}

Sinking of the Nile Delta region of Egypt is one of urgent issues to be investigated due to its vital importance to numerous perspectives such as economic, environmental and social impact on the whole Egyptian territory. This contribution represents one of the project outcomes entitled "Evaluation of Nile Delta Sinking Hypothesis Using the Global Positioning System (GPS), Tide Gauge and Satellite Altimetry and Gravity Techniques" that has been funded by the Science \& Technology Development FUND (STDF), Egypt in the period from 2013 till 2017. To detect the rates of the horizontal and vertical movements, three main geodetic techniques; Global Positioning System (GPS) measurements of Delta region, time-varying gravity models of the Gravity Recovery and Climate Experiment (GRACE) mission to monitor the temporal changes over the delta regions and satellite altimetry time series have been used. Our findings regarding the GPS technique show that the northern part of the Nile Delta region suffers from clear subsidence especially at the eastern and western side as represented by Port Said, Mansoura, Gamalyia, Alexandria and Edfena stations. The central part as well as the surrounding areas of Nile Delta suffers from clear uplift as represented by Tanta, Damnhour and Hamoul stations. Satellite gravity results show erosion rates of the conjunction part of Nile Delta and Mediterranean contact, especially at its eastern (Port Said surrounding areas) and western (Alexandria surrounding areas) parts. As we go inland to the southern part of the Nile Delta, the temporal gravity variations pattern decreases showing that the Delta subsidence follows the regular subsidence pattern, except that for the northern contact part of the Delta to the Mediterranean Sea. This is also supported by satellite altimetry missions which shows a continuously rising rate of the Mediterranean Sea level as detected from the Saral/AltiKa mission.
\end{abstract}




\section{Keywords}

Delta Subsidence, Deformation Parameters, Temporal Gravity Changes, Satellite Altimetry

\section{Introduction}

The Nile Delta is located in northern Egypt and has an area of about 22,000 $\mathrm{km}^{2}$. Its $225 \mathrm{~km}$ long, smooth coastline is located approximately $160 \mathrm{~km}$ north of Cairo, which resides at the apex of the delta. Figure 1 shows a topographic map of the Nile Delta of Egypt with its two main river branches; Rashid and Damietta with the locations of the used GPS Stations within this study. As seen in Figure 1, the heights decrease gently in the delta from south to north and along the coast of the Mediterranean Sea. With about 50 million people occupying its $22,000-\mathrm{km}^{2}$ area, the Nile Delta is one of the most densely populated areas on Earth (average population density of about 2300 people $/ \mathrm{km}^{2}$ ). About $97 \%$ of the Egyptian population lives on the Nile River banks and its delta, which compose approximately $4 \%$ of the total land area of Egypt.

Land subsidence is a major worldwide problem, particularly in vulnerable coastal areas such as the Nile Delta. Currently, it is of a major interest in the last decade to investigate whether or not the land surface of the Nile Delta is subsiding. The debate is certainly problematic in light of the fact that current measures of subsidence in the delta are rough estimates at best. Although numerous studies addressed the issue of the Delta land subsidence and tried to estimate the rate of Nile Delta sinking (e.g. Stanley, 1988; Stanley \& Warne, 1993; Ghoneim et al., 2004;

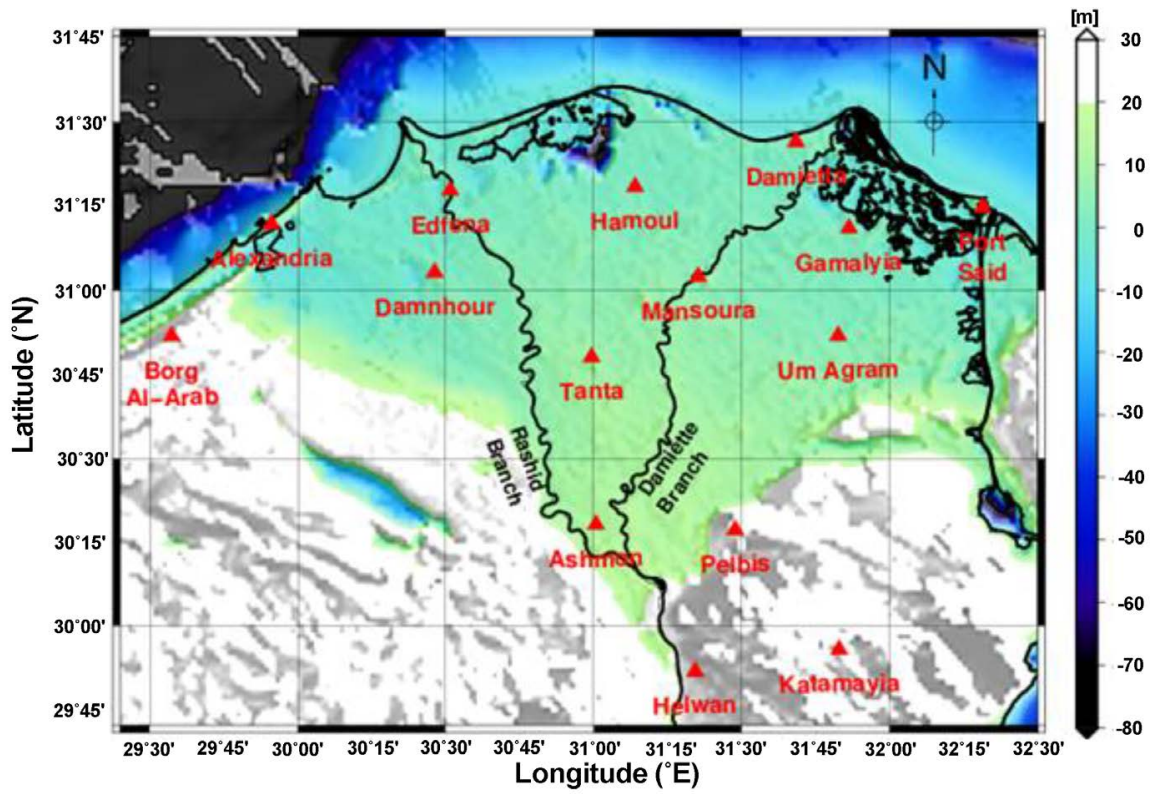

Figure 1. A topographic map of the Nile Delta of Egypt with its two main river branches; Rashid and Damietta, and the location of the GPS stations and the surrounding areas. 
Becker \& Sultan, 2009; Mohamed et al., 2015; El Bastawesy et al., 2016; Mohamed et al., 2016; Dawod et al., 2019), this paper uses for the first time a long time span of geodetic measurements of GPS time series, temporal solutions from the GRACE and altimetry missions. For instance, Stanley (1988) estimated the subsidence rates near the coast of the delta to be between $1.0-2.50 \mathrm{~mm} / \mathrm{yr}$ in the west and about $5.0 \mathrm{~mm} / \mathrm{yr}$ in the east based on radiocarbon dating of Holocene deltaic sediments. Stanley \& Warne (1993) reassessed these estimates and suggested that they were minimum rates because sediment reworking can cause radiocarbon dated cores to be older than the burial age. Subsidence rates estimated based on this geologic process assume uniform extension across the eastern and western parts of the delta, thus, yielding spatial and temporal averages that cannot assign unique rates to any particular region.

Ghoneim et al. (2004) used remote sensing techniques to depict the consequences on the Nile Delta of various climate change impact scenarios, ranging from conservative to extreme. She concluded that the Mediterranean Sea show increasing Sea Level Rise (SLR) with significantly increasing rate in the last few years. Becker \& Sultan (2009) used satellite-based radar interferometry (SAR) to measure the rate at which the surface sank between 1992 and 1999 by analyzing multiple radar images to measure changes in the altitude of thousands of landmarks such as buildings and utility poles. They found higher subsidence rates than those calculated by Stanley (1988), suggesting that some areas could be submerged sooner than already feared. In particular, the fastest rates were in the youngest sediments, such as those beneath the coastal city of Damietta.

In the current contribution, we present one of the main outcomes of the project entitled "Evaluation of Nile Delta Sinking Hypothesis Using the Global Positioning System (GPS), Tide Gauge and Satellite Altimetry and Gravity Techniques" that has been funded by the STDF, Egypt in the period from 2013 till 2017. We provide here the results using three main geodetic data scenarios from Global Positioning System (GPS), Gravity Recovery and Climate Experiment (GRACE) time-varying and satellite altimetry time series. This will be organized as follows: Section 2 reviews briefly the establishment of GPS network and show the results. Then, the temporal variations obtained from the GRACE mission are given in Section 3. Section 4 discusses the results of sea level variations obtained from satellite altimetry missions. Finally, on this basis, a general conclusion is outlined in Section 5.

\section{GPS Dataset and Time Series Analysis of the Nile Delta and Its Surroundings}

Fifteen GPS stations have been established by the National Research Institute of Astronomy and Geophysics (in Helwan, Cairo, Egypt) to cover the Nile Delta and its surrounding areas as shown in Figure 1, eleven stations of them are permanent stations and the other four stations are non-permanent ((Tanta, Ashmon, Pelbis and Um Agram (Fakus)). These stations are ranging from coastal locations, middle and deep on land locations. Geographic coordinates, abbreviations 
and observation starting date of each GPS station are given on Table 1.

Since October 2013, campaigns are repeated every three months for the four non-permanent GPS stations, in addition to the fifteen permanent GPS stations that are working continuously. There are some stations still have little data to be processed, so we processed the satisfied data either permanent or campaigns and they were processed together using Bernese V. 0.5 (Dach et al., 2007) and precise coordinates of points of the network were computed in International Terrestrial Reference Frame (ITRF 2008). The data were processed day by day, and normal equations for all the days of each campaign were stored. Then, these normal equations were combined to obtain final solution for each campaign. Precise ephemeris was used besides using of IGS stations (MATE, NICO, and NOT 1).

All GPS observation epochs have been used to estimate the Nile Delta horizontal and vertical crustal deformation parameters which are given as:

$$
\begin{gathered}
x(t)=x\left(t_{0}\right)+V_{x}\left(t_{0}\right)\left(t-t_{0}\right) \\
y(t)=y\left(t_{0}\right)+V_{y}\left(t_{0}\right)\left(t-t_{0}\right) \\
z(t)=z\left(t_{0}\right)+V_{z}\left(t_{0}\right)\left(t-t_{0}\right) \\
V=\sqrt{V_{x}^{2}+V_{y}^{2}+V_{z}^{2}}
\end{gathered}
$$

where:

$x(t), y(t)$ and $z(t)$ are the positions at north horizontal, east horizontal and vertical directions, respectively, $V$ is the velocity, $t$ is the current year of

Table 1. Description of the Nile Delta GPS stations.

\begin{tabular}{cccccc}
\hline Station Name & Abbreviations & Latitude $\left(^{\circ}\right)$ & Longitude $\left(^{\circ}\right)$ & Elevation $(\mathrm{m})$ & Start Date \\
\hline Alexandria & ALEX & $31: 11: 49.43277$ & $29: 54: 39.56536$ & 57.995 & $1-2-2006$ \\
Borg Al-Arab & BORG & $30: 51: 48.0919$ & $29: 34: 25.3259$ & 98.0913 & $23-6-2009$ \\
Damietta & DAMT & $31: 26: 23.15165$ & $31: 40: 59.32017$ & 43.599 & $26-2-2014$ \\
Gamalyia & GAMA & $31: 11: 02.997537$ & $31: 51: 44.00408$ & 32.4096 & $5-12-2013$ \\
Hamoul & HAML & $31: 18: 25.30198$ & $31: 08: 22.358$ & 23.848 & $3-12-2013$ \\
Helwan & PHLW & $29: 51: 41.6139$ & $31: 20: 36.23244$ & 153.6389 & $21-12-2006$ \\
Katamayia & KATA & $29: 55: 39.1083$ & $31: 49: 45.21059$ & 502.173 & $18-12-2010$ \\
Mansoura & MANS & $31: 02: 27.69883$ & $31: 21: 09.37737$ & 39.588 & $20-1-2011$ \\
Port Said & PORT & $31: 14: 44.5042$ & $32: 18: 51.623$ & 41.977 & $1-1-2013$ \\
Edfena & EDFE & $31: 17: 45.118$ & $30: 30: 55.521$ & 35.822 & $28-4-2014$ \\
Damnhour & DAMN & $31: 03: 12.12833$ & $30: 27: 45.56877$ & 47.928 & $24-2-2014$ \\
Pelbis & PLBS & $30: 17: 09.12807$ & $31: 28: 40.85530$ & 164 & $1-3-2009$ \\
Um Agram & AGRM & $30: 51: 53.43316$ & $31: 49: 33.22390$ & 32.39 & $1-3-2014$ \\
Ashmon & ASHM & $30: 18: 07.33301$ & $31: 00: 27.20786$ & 47.1 & $8-12-2004$ \\
Tanta & TNTA & $30: 48: 04.7170$ & $30: 59: 34.6247$ & 51.57 & $1-3-2014$ \\
\hline
\end{tabular}


observation, and $t_{0}$ is the reference year of observation. The program ADDNEQ2 of Bernese V 5.5.0 (Dach et al., 2007) was applied to estimate the horizontal and vertical velocities for each station of network. Estimated regional and local horizontal parameters as well as vertical velocity parameters rates are given in Table 2 and Figures 2-4 respectively.

Table 2. Regional, local horizontal and vertical velocity parameters of GPS stations.

\begin{tabular}{|c|c|c|c|c|c|c|c|c|}
\hline \multirow{2}{*}{ Station Nam } & \multirow{2}{*}{ Abbr. } & \multicolumn{3}{|c|}{ Reg. Horizontal Velocity Para. } & \multicolumn{3}{|c|}{ Loc. Horizontal Velocity Para. } & \multirow{2}{*}{$\begin{array}{l}\text { Vertical Velocity } \\
\qquad \text { V (m) }\end{array}$} \\
\hline & & $\mathrm{Ve}(\mathrm{m})$ & $\operatorname{Vn}(\mathrm{m})$ & Mean V (m) & $\operatorname{Ve}(\mathrm{m})$ & $\operatorname{Vn}(\mathrm{m})$ & Mean V (m) & \\
\hline Alexandria & ALEX & 0.0368 & 0.0070 & 0.037 & 0.0128 & -0.0129 & 0.0181 & -0.0068 \\
\hline Borg-Elarab & BORG & 0.0236 & 0.0164 & 0.0287 & -0.0003 & -0.0036 & 0.00360 & 0.0008 \\
\hline Damietta & DAMI & 0.0347 & 0.0149 & 0.0377 & 0.0105 & -0.0049 & 0.011 & -0.0027 \\
\hline Gamalyia & GAML & 0.0195 & 0.0175 & 0.0262 & -0.0048 & -0.0022 & 0.0052 & -0.032 \\
\hline Hamoul & HAMO & 0.0178 & 0.0189 & 0.0259 & -0.0064 & -0.0009 & 0.0064 & 0.0019 \\
\hline Helwan & PHLW & 0.0223 & 0.0176 & 0.0284 & -0.0021 & -0.0022 & 0.00304 & 0.0012 \\
\hline Katamia & KATA & 0.0221 & 0.0169 & 0.0278 & -0.0023 & -0.0028 & 0.0036 & 0.0022 \\
\hline Mansoura & MANS & 0.0268 & 0.0158 & 0.031 & 0.0025 & -0.0040 & 0.0047 & -0.011 \\
\hline Port Said & PORT & 0.0235 & 0.0238 & 0.033 & -0.0009 & 0.0041 & 0.0041 & -0.0079 \\
\hline Edfena & EDFE & 0.0119 & 0.0129 & 0.0175 & -0.0121 & -0.0070 & 0.013 & -0.0130 \\
\hline Damanhour & HOUR & 0.0185 & 0.0223 & 0.0289 & -0.0056 & 0.0023 & 0.0060 & 0.0279 \\
\hline Pelbis & BILB & 0.0202 & 0.0158 & 0.256 & -0.0041 & -0.0039 & 0.0056 & -0.0027 \\
\hline Um Agram & AGRM & 0.0214 & 0.0204 & 0.029 & -0.0030 & 0.0006 & 0.003 & -0.0084 \\
\hline Ashmon & ASHM & 0.0197 & 0.0139 & 0.0241 & -0.0046 & -0.0059 & 0.0074 & -0.0049 \\
\hline Tanta & TNTA & 0.0249 & 0.0264 & 0.036 & 0.0008 & 0.0065 & 0.0065 & 0.011 \\
\hline
\end{tabular}

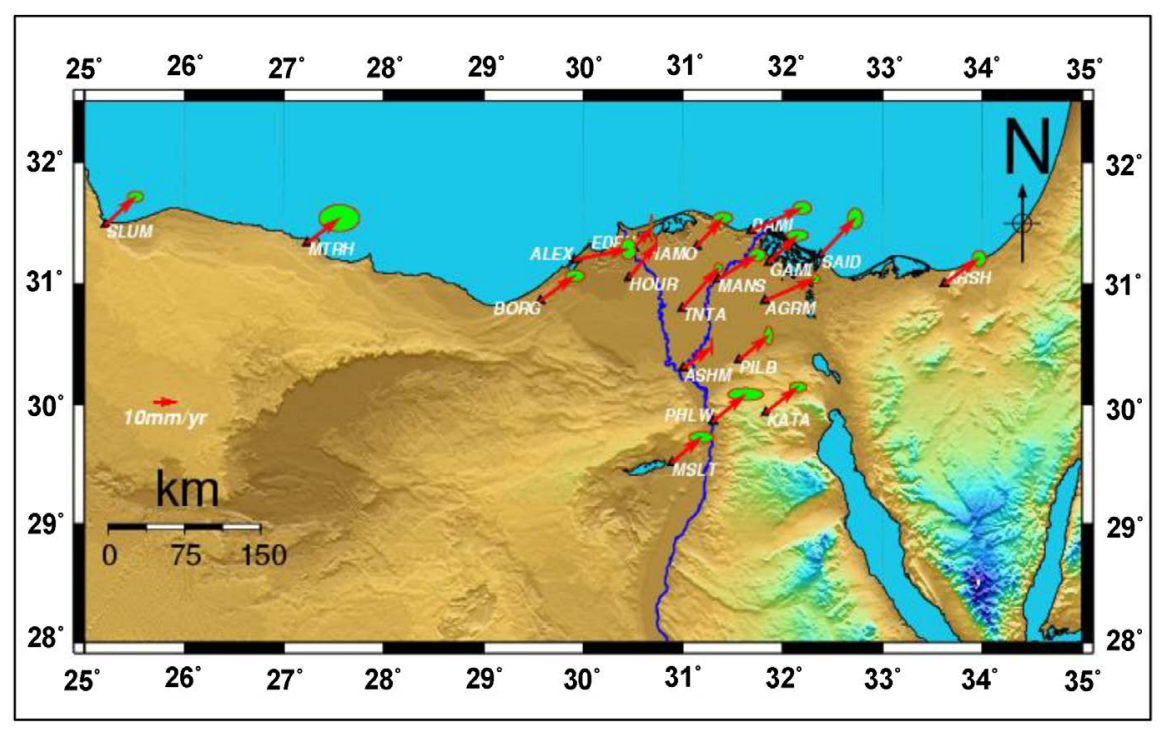

Figure 2. The estimated regional horizontal velocity field in ITRF 2008 derived from the Bernese software, with $95 \%$ confidence regions from the scaled standard deviation ( $\sigma$ ). 


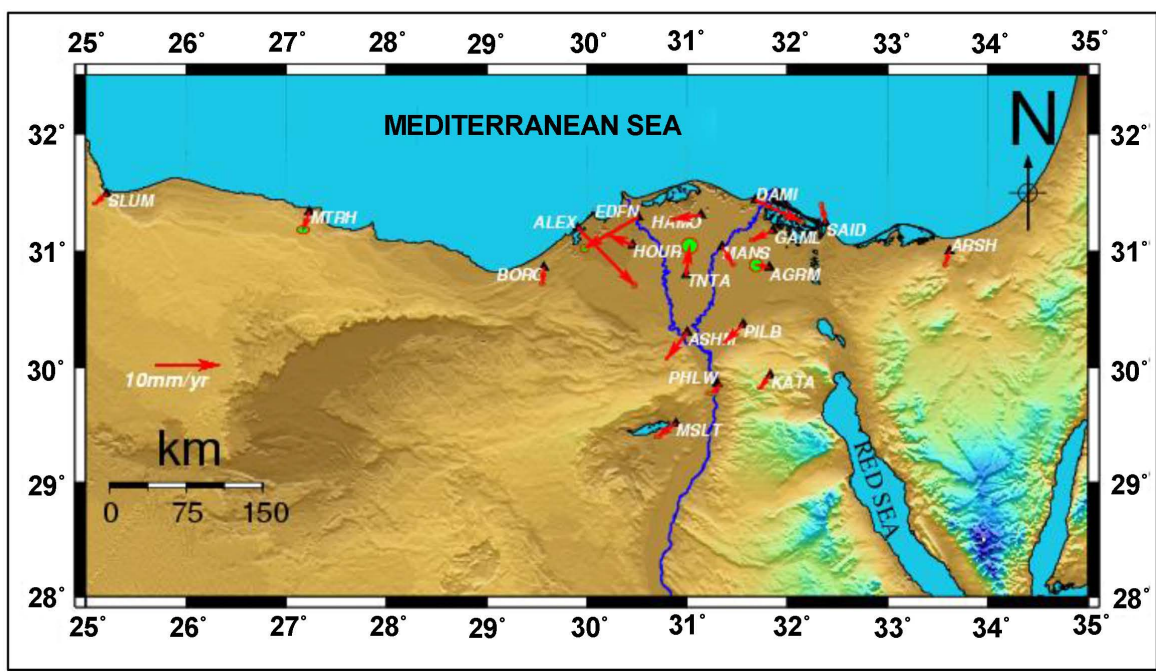

Figure 3. The estimated local horizontal velocity field in ITRF 2008 derived from the Bernese software, with $95 \%$ confidence regions from the scaled standard deviation ( $\sigma$ e).

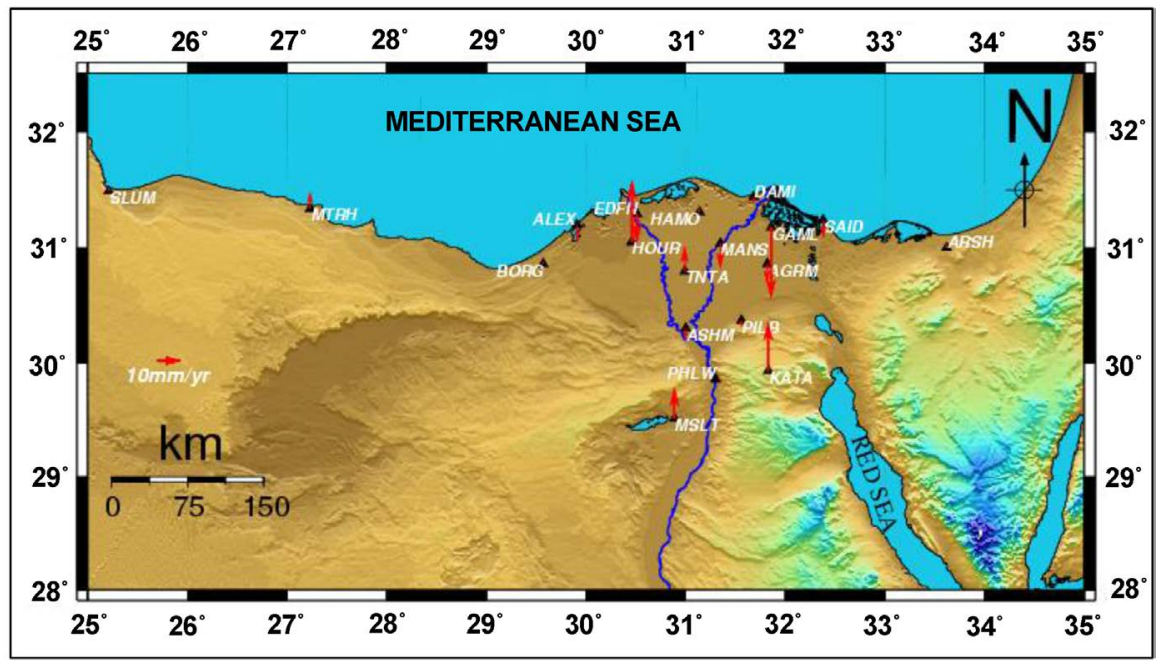

Figure 4. The estimated vertical velocity field in ITRF 2008 derived from the Bernese software, with $95 \%$ confidence regions from the scaled standard deviation ( $\sigma$ e).

One should note here, that the latitudes and longitudes of Figures 2-4 have been extended from Figure 1 to show the relationship between the horizontal and vertical motion of the Nile Delta as given in Table 1 and Table 2 and the distant 4 permanent GPS stations established by the National Research Institute of Astronomy and Geophysics. These four stations are Arish (ARSH) in the eastern part, Marsa Matrouh (MARS) and Salum (SLUM) in the western part and Mesalat (MESA) in the southern part of the Nile Delta.

One can infer from these findings that the horizontal movement of the Nile Delta obeys to a great extent the regional tectonic settings of the relative movements among African, Eurasian and Arabian plates as shown in Figure 2. As these movements are so strong, it might masks any local movements within the Delta. Therefore, it is important to remove the regional movement trend to re- 
veal any possible local horizontal crustal deformation. Global kinematic model (NUVEL-1A) (DeMets et al., 1990) has been used to estimate the regional trends along the Delta. Regional velocities have been removed from the observations revealing the local horizontal velocities. Estimated local horizontal parameters are given at Figure 3. The revealed local horizontal velocities shows that the Delta is not deformed uniformly and it comprises of minor blocks. This suggests that possible Nile Delta subsidence has heterogeneous behavior.

However, vertical velocities would be the most informative source of data concerning the Nile Delta subsidence. Vertical velocities reflect directly the subsidence and uplift of any location. Estimated vertical parameters are given at Figure 4, which shows significant pattern of subsidence ad uplift. High rate of uplift can be detected at the Nile Delta Mediterranean junction with higher subsidence to the east. Remarkable subsidence zone can be seen at the eastern edge of the Delta inland, which suggest that Mediterranean not only the effective subsidence factor to the Delta. High heterogeneities can be realized along the Delta. This can be seen as variable rate of subsidence from one side and the appearance of some other uplift locations.

\section{Temporal Gravity Field Solutions from Satellite Gravimetry over the Nile Delta}

Unconstrained (i.e. non-filtered) as well as de-correlated filtered temporal (here monthly) gravity field anomalies have been driven from the period Apr. 2002-Jun. 2017 as determined from the ITSG-Grace 2016 temporal gravity field solutions (Mayer-Gürr et al., 2016), which has been derived from GRACE observations as shown in Figure 5. Figure 5(a) and Figure 5(b) show a mean static gravity signal dominating the temporal gravity solution. This signal can be seen in details from the static gravity solution derived from the Eigen-6C4 geopotential model in a resolution of $5^{\prime} \times 5^{\prime}$ as shown in Figure 6 .

When the mean static signal subtracted from the unconstrained temporal solution, distortion contaminating the monthly GRACE gravity solution in longitudinal striping pattern is visible in as shown in Figure 5(c). This striping pattern is dominant due to the GRACE satellite configuration flying in a north-south direction. One finds that the striping structure of the GRACE solution is strongly dampened (see Figure 5(d) when decorrelated filter is applied represented by ITSG-Grace 2016 DDK5 (see Kusche, 2007) gravity solutions.

In Figure 6, one can see that the Mediterranean/Nile Delta conjunction shows slight positive free-air gravity anomalies reaching about $60 \mathrm{mGal}$ in the front of the middle Nile Delta (see Figure 6, right). The transition in thickness and density from oceanic to continental crust is one of the major reasons for changing the negative gravity values to positive ones. For instance, In Mediterranean/Nile Delta area, gravity is strongly correlated with crustal thickness and composition, and hence, this gravity anomaly reaching $60 \mathrm{mGal}$ in the middle area of the Nile Delta (north of Baltim) is due to the increase in sediments thickness comparable to the oceanic/sea (Middle of Mediterranean) crust. 

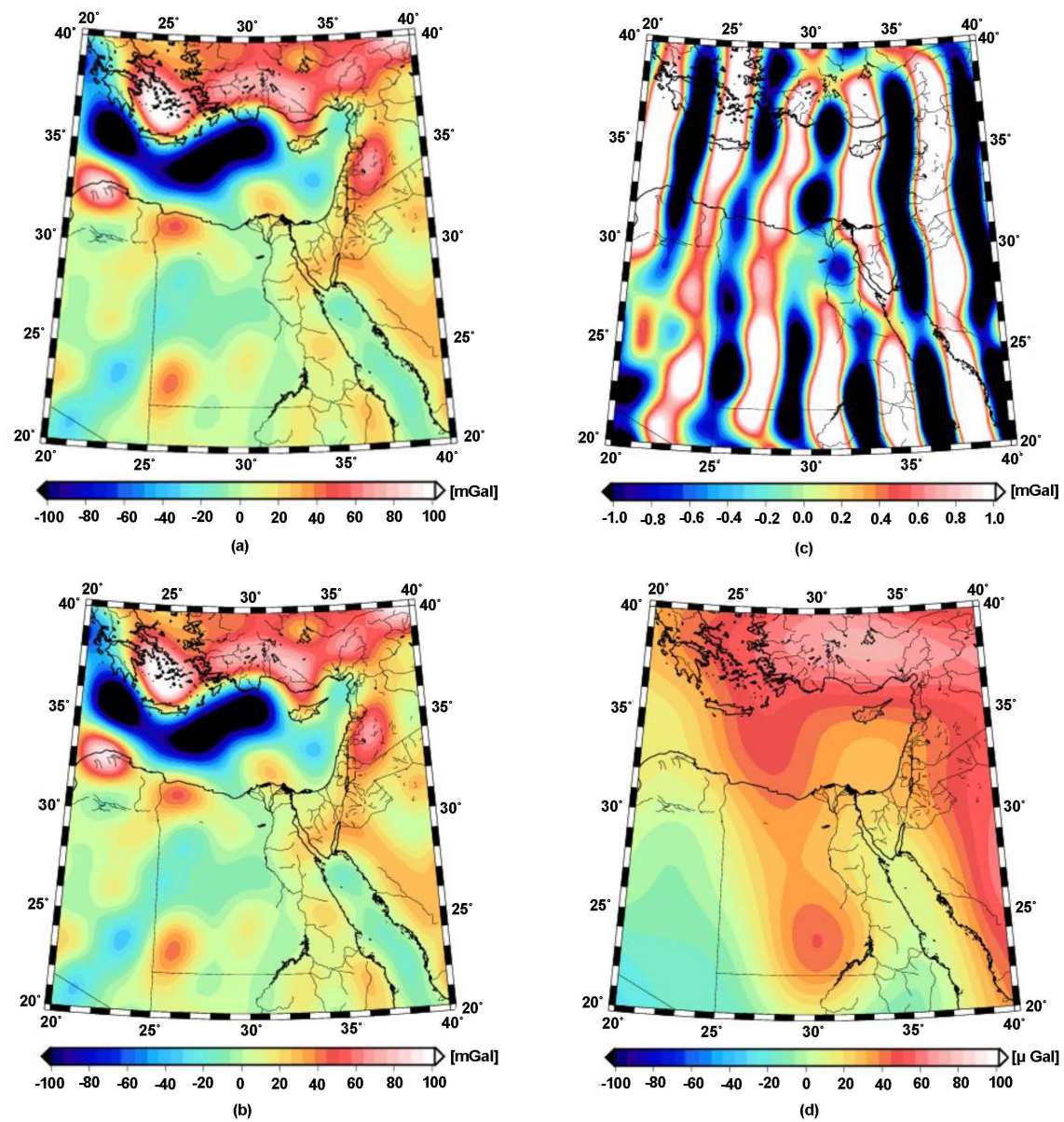

Figure 5. Mean GRACE temporal gravity anomalies over Egyptian and Mediterranean Sea region from 04.2002 to 06.2017 . (a) and (b): temporal mean gravity anomalies derived from the unconstrained and de-correlated filtered ITSG-Grace 2016 temporal gravity field solutions, respectively; (c) and (d): gravity anomalies after subtracting the mean signal. [Please note the different color scales].

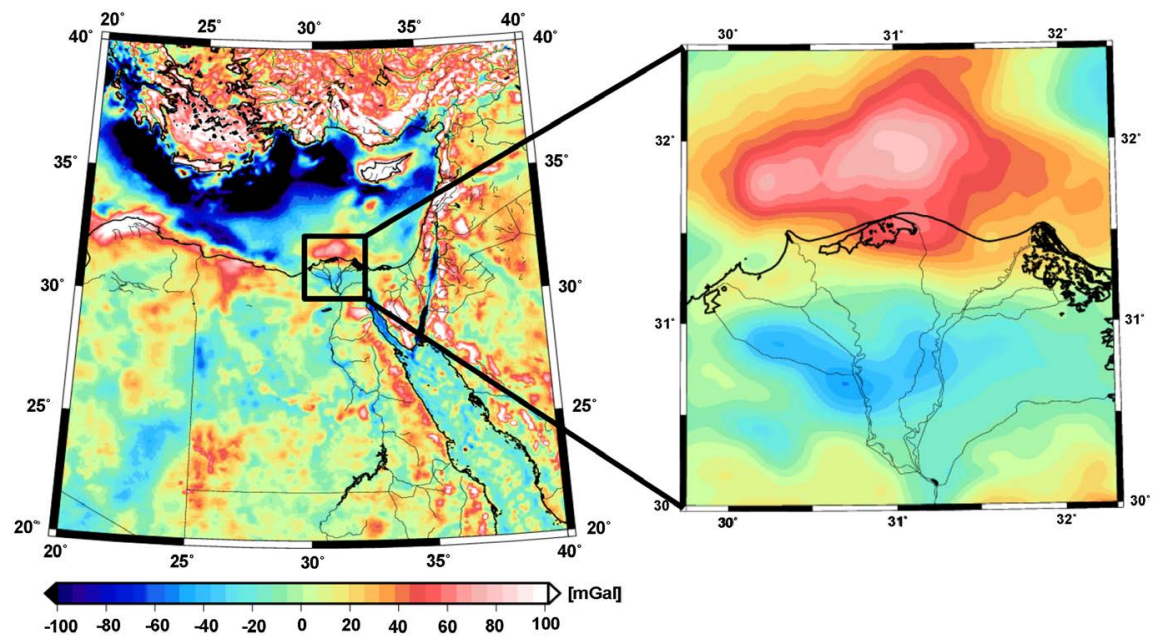

Figure 6. Free-air gravity field anomalies as estimated from eigen $6 \mathrm{c} 4(\approx$ spatial resolution of $5^{\prime} \times 5^{\prime}$ ) geopotential model over Egyptian-Mediterranean Sea region (left) and over a zoomed in area of the Mediterranean/Nile Delta conjunction (right). 
The most important feature can be seen is that the gravity value of $60 \mathrm{mGal}$ is decreasing toward the East of the Nile Delta reaching about $22 \mathrm{mGal}$ (north of Port Said) and toward the West of the Nile Delta reaching about $8 \mathrm{mGal}$ (north of Alexandria) till it reaches about $-5 \mathrm{mGal}$ at the southern area of Alexandria. This would emphasize that the sediments are decreasing slightly in the western and eastern parts of the Nile Delta more than its northern part.

So the last addressed points still support our idea about subsidence and high erosion rates of the conjunction part of Nile Delta and Mediterranean contact, especially at its eastern (Port Said surrounding areas) and western (Alexandria surrounding areas) parts. The decrease of the temporal gravity variation pattern as we go inland to the southern of the Nile Delta, shows that the Delta subsidence follow the regular subsidence pattern, except that for the northern contact part of the Delta to the Mediterranean Sea.

\section{Mean Sea Level Rise of Mediterranean Sea from Satellite Altimetry}

Since the Mediterranean Sea is bordered the Nile Delta in the northern part, it is then quite important to investigate the behavior of the sea level rise in the Mediterranean region. Therefore, we have used satellite altimeter data provided by the CNES-AVISO+ to estimate the Mediterranean Sea level rise based on measurements from satellite radar altimeters. So, the time series data have been downloaded from the CNES-AVISO+ official website:

(https://www.aviso.altimetry.fr/en/data/products/) available for US altimetry missions; TOPEX/Poseidon (T/P), Jason-1, and Jason-2, which have monitored the same ground track since 1992 and the ESA missions; ERS-1, ERS-2 and Envisat in addition to the most current satellite altimetry missions Jason-3 and Saral/AltiKa.

In this study, two types of dataset have been represented including the mean sea level of the Mediterranean Sea before and after removing the seasonal signals. Figure 7(a) shows the Mediterranean Sea rise attaining the seasonal signals, while Figure 7(b) shows satellite altimeter Mediterranean Sea rise after removing the seasonal signals from Dec. 1992 till Dec. 2018.

In addition, we have plotted the MSL of the Mediterranean Sea before and after removing of the seasonal signal only from the Topex/Poseidon (T/P) as one of the earlier satellite altimetry missions and Saral/AltiKa as one of the current missions as shown in Figure 8. The expressions (retained) and (removed) inside the figure stand for retained and removed trend of the seasonal signal, respectively.

One can infer from Figure 7 and Figure 8 that the MSL of the Mediterranean Sea has been increasing since the end of 1992 up till now. The statistics of the investigated satellite altimetry missions as indicated in Figure 7 in terms of minimum, maximum, mean and standard deviations of the MSL are given in Table 3 and Table 4 . Considering Table 4, where the seasonal signal has been removed, we find that the maximum sea level rise that was detected by the earlier 


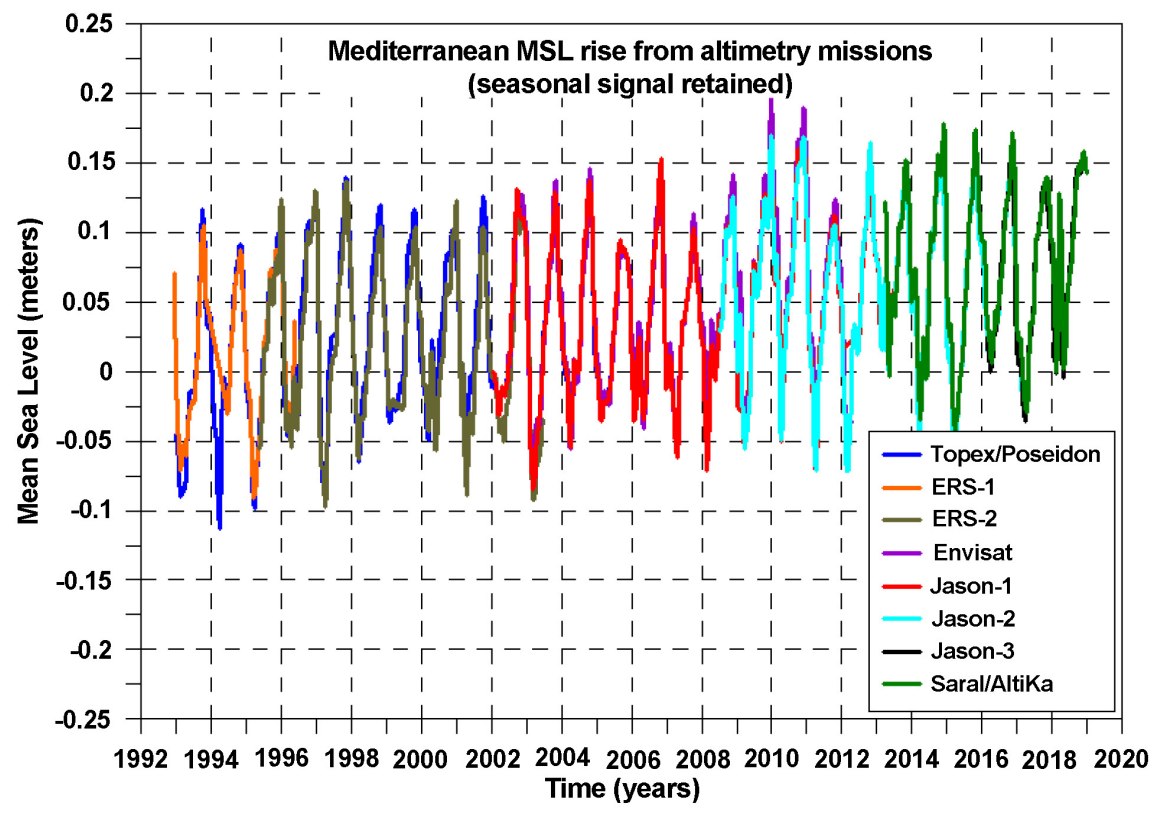

(a)

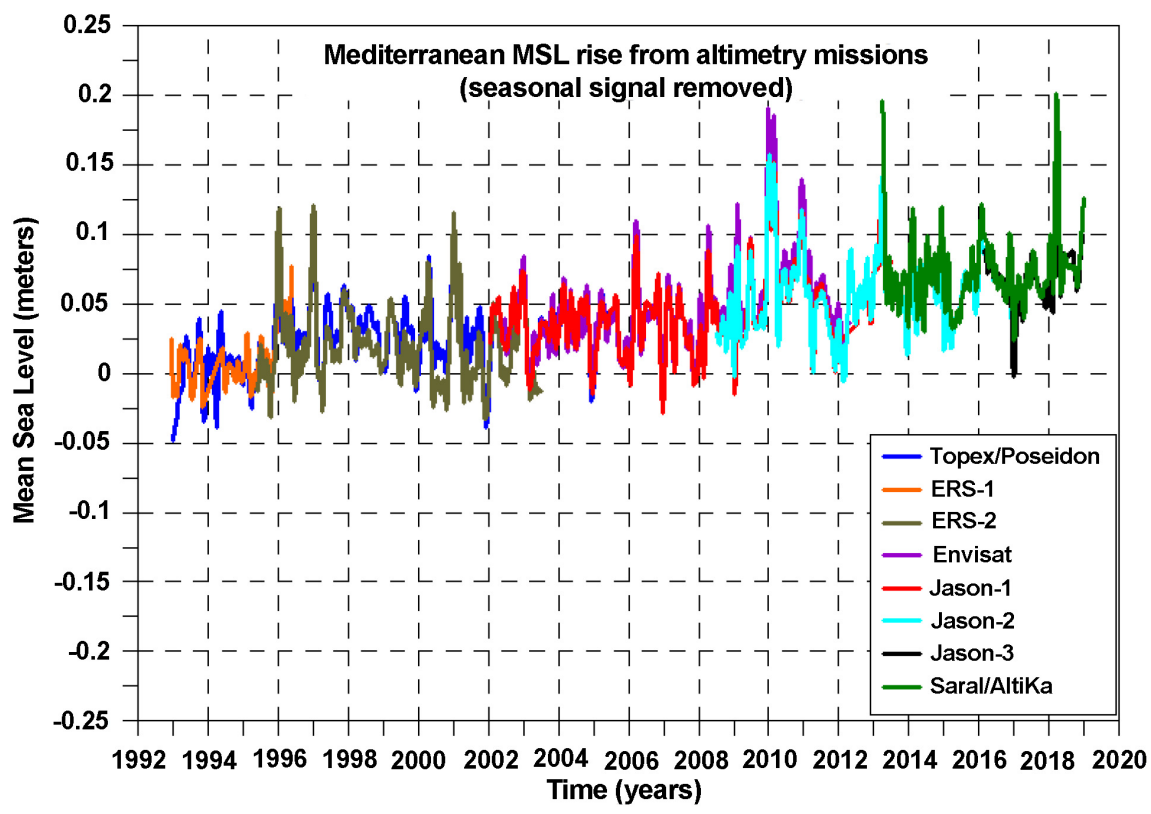

(b)

Figure 7. Mediterranean seasonal mean sea level (MSL) rise in [meter] with retained trend of the seasonal signal (a) and after removing the trend of the seasonal signal (b) from multiple altimetry missions from Dec. 1992 till Dec. 2018.

mission Topex/Poseidon was about $11.25 \mathrm{~cm}$, whereas in March 2018, a maximum MSL rise of about $20.12 \mathrm{~cm}$ has detected by the Saral/AltiKa as shown in Figure 8.

On the spatial scale, the marked variability of the sea-level trend from the reference altimetry mission products which are computed with the Topex/Poseidon, Jason-1, Jason-2 and Jason-3 series for the time series and with merged datasets 


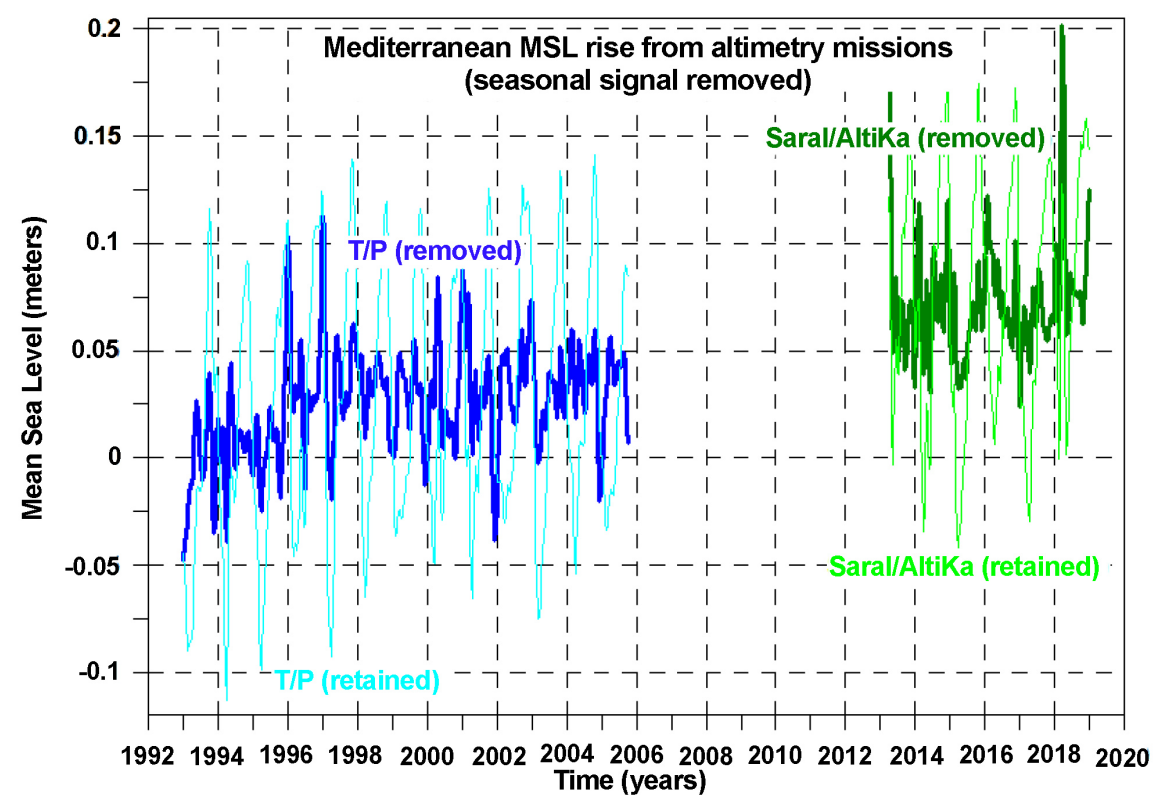

Figure 8. Mediterranean mean sea level (MSL) rise in [meter] as determined from T/P as one of the earlier satellite altimetry missions and Saral/AltiKa as one of the current missions. The expressions (retained) and (removed) stand for retained and removed trend of the seasonal signal, respectively.

Table 3. Statistics of the MSL in [cm] from the investigated satellite altimetry missions indicated in Figure 7(a), seasonal signal retained.

\begin{tabular}{ccccccc}
\hline $\begin{array}{c}\text { Satellite Altimetry } \\
\text { mission }\end{array}$ & Period [year] & Min. & Max. & Mean & St. Dev. & Trend [cm/y] \\
\hline T/P & $93-05$ & -11.27 & 14.14 & 2.43 & 5.93 & 0.295 \\
ERS-1 & $92-96$ & -9.08 & 11.56 & 0.92 & 5.43 & 1.046 \\
ERS-2 & $95-03$ & -9.77 & 13.59 & 1.91 & 5.79 & -0.283 \\
Jason-1 & $02-13$ & -8.46 & 16.87 & 4.27 & 5.82 & 0.452 \\
Jason-2 & $08-17$ & -7.13 & 16.92 & 5.87 & 5.85 & 0.095 \\
Jason-3 & $16-18$ & -3.58 & 16.02 & 7.02 & 5.48 & 2.454 \\
Envisat & $02-12$ & -7.79 & 20.02 & 4.70 & 5.97 & 0.351 \\
Saral/AltiKa & $13-18$ & -4.20 & 17.82 & 7.47 & 5.65 & 0.494 \\
\hline
\end{tabular}

for their maps is represented in Figure 9. As seen, there are positive values in most of the eastern (in the front of the Damietta branch) and western (in the front of the Rashid branch) (see Figure 1) parts of the Mediterranean Sea/Nile Delta contact, which emphasizes that recurrent gyres and eddies in the circulation are found. Maximum positive values, with more than $6 \mathrm{~mm} /$ year, have been also found at the location of the Mersa-Matruh gyre, i.e. in the western part of the Rashid branch of the Nile Delta. This may be attributed to the contribution of the mission Topex/Poseidon happened in 1996 and 1997, which may be due to atmospheric pressure, observed a large scale zonal gradient, which produces higher sea-level values and a larger variance in the sea-level signal in the eastern part 
Table 4. Statistics of the MSL in $[\mathrm{cm}]$ from the investigated satellite altimetry missions indicated in Figure 7(b), seasonal signal removed.

\begin{tabular}{ccccccc}
\hline $\begin{array}{c}\text { Satellite Altimetry } \\
\text { mission }\end{array}$ & Period [year] & Min. & Max. & Mean & St. Dev. & Trend [cm/y] \\
\hline T/P & $93-05$ & -4.81 & 11.25 & 2.53 & 2.53 & 0.240 \\
ERS-1 & $92-96$ & -2.64 & 11.22 & 1.12 & 2.54 & 1.113 \\
ERS-2 & $95-03$ & -3.30 & 12.07 & 1.91 & 2.86 & -0.149 \\
Jason-1 & $02-13$ & -2.81 & 15.30 & 4.28 & 2.94 & 0.344 \\
Jason-2 & $08-17$ & -0.59 & 15.74 & 5.68 & 2.84 & 0.138 \\
Jason-3 & $16-18$ & -0.213 & 17.97 & 6.94 & 2.59 & -0.773 \\
Envisat & $02-12$ & -2.78 & 19.03 & 4.62 & 3.23 & 0.417 \\
Saral/AltiKa & $13-18$ & 2.40 & 20.12 & 7.30 & 2.75 & -0.201 \\
\hline
\end{tabular}

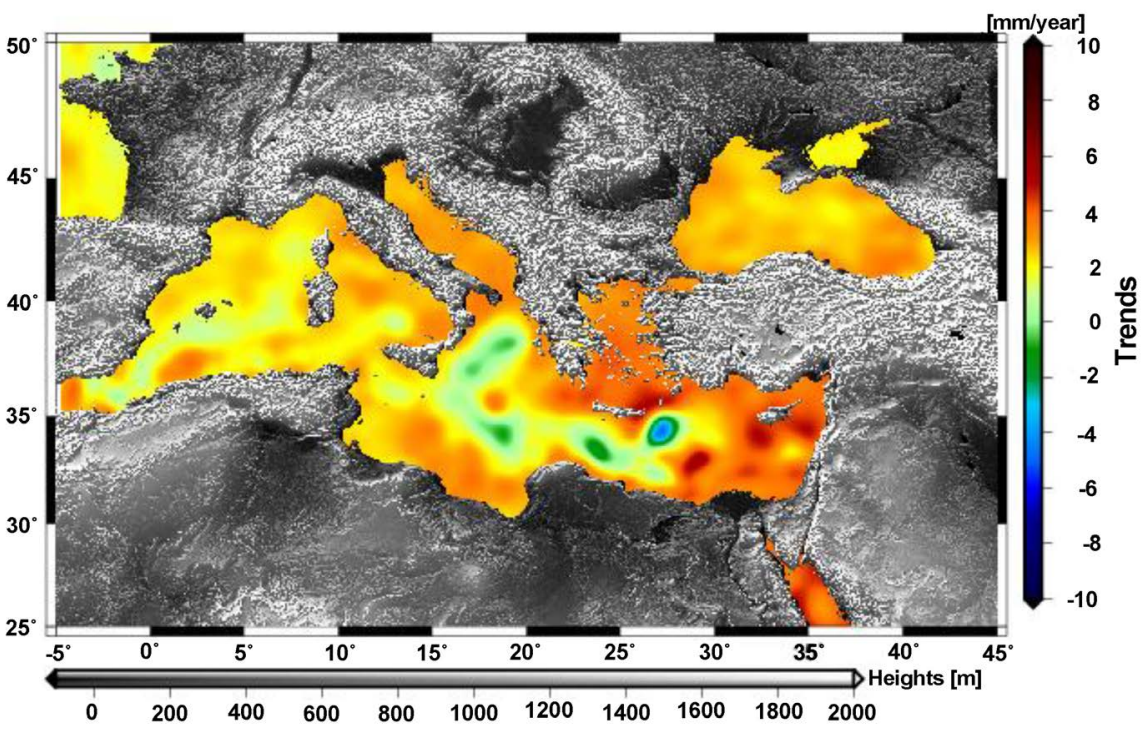

Figure 9. Mediterranean mean sea level (MSL) trends in [mm/year] for the reference altimetry mission products. Seasonal signal removed.

of the Mediterranean region (Oddo et al., 2014). These events have already been observed at the basin scale (Calafat et al., 2012; Tsimplis et al., 2013) and defined as non-steric fluctuations due to mass transport through the Strait of Gibraltar driven by wind, occurring during a strong negative phase of the North Atlantic Oscillation (Landerer \& Volkov, 2013).

Our findings show clearly a mean sea level rise especially in the front of the Nile Delta. This would support the idea about subsidence and high erosion rates of the conjunction part of Nile Delta and Mediterranean contact, especially at its eastern (Damietta and Port-Said) and western (Alexandria surroundings) parts.

\section{Conclusion}

In this manuscript, we have monitored the behavior of the Nile Delta subsidence rate in conjunction with the Mediterranean Sea level rise using different ground- 
and satellite-based datasets of Global Positioning System (GPS), satellite-based gravity temporal and mean-static geopotential models and satellite-based altimetry time series.

The Global Positioning System (GPS) ground measurements were responsible for detecting the rates of the horizontal and vertical movements of Delta region. The gravity models stood in our study for monitoring the temporal changes as well as the high resolved mean-static gravity signal over the delta regions, whereas the satellite altimetry time series have been used for tying the change in the sea level of the Mediterranean Sea in front of the Delta region with the vertical motion of the Nile Delta.

Regarding to the GPS outcome, our findings show that the northern part of the Nile Delta region suffers from clear subsidence especially at the eastern and western side as represented by Port Said, Mansoura, Gamalyia, Alexandria and Edfena stations. The central part as well as the surrounding areas of Nile Delta suffers from clear uplift as represented by Tanta, Damnhour and Hamoul stations.

According to the results derived from geopotential temporal and mean-static gravity models, erosion rates of the conjunction part of Nile Delta and Mediterranean contact are shown, especially at its eastern (Port Said surrounding areas) and western (Alexandria surrounding areas) parts. The temporal gravity variations pattern decreases as we go inland to the southern part of the Nile Delta showing that the Delta subsidence follows the regular subsidence pattern, except that for the northern contact part of the Delta to the Mediterranean Sea. This has been also supported by satellite altimetry missions that show a continuously rising rate of the Mediterranean Sea level as detected from the Saral/AltiKa mission.

\section{Acknowledgements}

This work was carried out within the framework of the project entitled "Evaluation of Nile Delta Sinking Hypothesis Using the Global Positioning System (GPS), Tide Gauge and Satellite Altimetry and Gravity Techniques" that has been funded by the Science \& Technology Development FUND (STDF), Egypt in the period from 2013 till 2017, so we thank the staff members of STDF for their support.

\section{Conflicts of Interest}

The authors declare no conflicts of interest regarding the publication of this paper.

\section{References}

Becker, R., \& Sultan, M. (2009). Land Subsidence in the Nile Delta: Inferences from Radar Interferometry. The Holocene, 19, 949-954. https://doi.org/10.1177/0959683609336558

Calafat, F. M., Jorda, G., Macros, M., \& Gomis, D. (2012). Comparison of Mediterranean Sea Level Variability as Given by Three Baroclinic Models. Journal of Geophysical Research, 117, C02009. https://doi.org/10.1029/2011JC007277

Dach, R., Hugentobler, U., Fridez, P., \& Meindl, M. (2007). Bernese GPS Software Ver- 
sion 5.0. Bern: Astronomical Institute, University of Bern.

Dawod, G., Mohamed, H., \& Haggag, G. (2019). Relative and Absolute Sea Level Rise Based on Recent Heterogeneous Geospatial Data: A Case Study in the Nile Delta, Egypt. Journal of Scientific and Engineering Research, 6, 55-64.

DeMets, C., Gordon, R. G., Argus, D. F., \& Stein, S. (1990). Current Plate Motions. Geophysical Journal International, 101, 425-478. https://doi.org/10.1111/j.1365-246X.1990.tb06579.x

El Bastawesy, M., Cherif, O. H., \& Sultan, M. (2016). The Geomorphological Evidences of Subsidence in the Nile Delta: Analysis of High Resolution Topographic DEM and Multi-Temporal Satellite Images. Journal of African Earth Sciences, 136, 252-261. https://doi.org/10.1016/j.jafrearsci.2016.10.013

Ghoneim, E., Koch, M., \& El-Baz, F. (2004). Modeling Flash Flood Hazards in an Arid Region by Remote Sensing. In 32nd International Geological Congress (Session 262, Paper 5, p. 1180), 20-28 August 2004, Florence, Italy.

Kusche, J. (2007). Approximate Decorrelation and Non-Isotropic Smoothing of Time-Variable GRACE-Type Gravity Field Models. Journal of Geodesy, 81, 733-749.

https://doi.org/10.1007/s00190-007-0143-3

Landerer, F. W., \& Volkov, D. L. (2013). The Anatomy of Recent Large Sea Level Fluctuations in the Mediterranean Sea. Geophysical Research Letters, 40, 553-557. https://doi.org/10.1002/grl.50140

Mayer-Gürr, T., Behzadpour, S., Ellmer, M., Kvas, A., Klinger, B., \& Zehentner, N. (2016). ITSG-Grace 2016 Monthly and Daily Gravity Field Solutions from GRACE. GFZ Data Services.

Mohamed, A., Radwan, A., Sharaf, M., Hamimi, Z., Hegazy, E., Aly, N., \& Gomaa, M. (2016). Evaluation of the Deformation Parameters of the North Part of Egypt Using Global Navigation Satellite System (GNSS). NRIAG Journal of Astronomy and Geophysics, 5, 65-75. https://doi.org/10.1016/j.nrjag.2016.01.001

Mohamed, H., Shaheen, B., Hosney, M., \& Dawod, G. (2015). High-Precision GPS Monitoring of the Land Subsidence in the Nile Delta: Status and Preliminary Results. In Regional Conference on Surveying and Development, 3-6 October 2015, Sharm El-Sheikh, Egypt.

https://www.researchgate.net/publication/282365658_High-Precision_GPS_Monitorin g_of_the_Land_Subsidence_in_the_Nile_Delta_Status_and_Preliminary_Results

Oddo, P., Bonaduce, A., Pinardi, N., \& Guarnieri, A. (2014). Sensitivity of the Mediterranean Sea Level to Atmospheric Pressure and Free Surface Elevation Numerical Formulation in NEMO. Geoscientific Model Development, 7, 3001-3015.

https://doi.org/10.5194/gmd-7-3001-2014

Stanley, D. (1988). Subsidence in the Northeastern Nile Delta: Rapid Rates, Possible Causes, and Consequences. Science, 240, 497-500. https://doi.org/10.1126/science.240.4851.497

Stanley, D., \& Warne, A. (1993). Nile Delta, Recent Geological Evolution and Human Impact. Science, 260, 628-634. https://doi.org/10.1126/science.260.5108.628

Tsimplis, M. N., Calafat, F. M., Marcos, M., Jordà, G., Gomis, D., Fenoglio-Marc, L., Struglia, M. V., Josey, S. A., \& Chambers, D. P. (2013). The Effect of the NAO on Sea Level and on Mass Changes in the Mediterranean Sea. Journal of Geophysical Research: Ovceans, 118, 944-952. https://doi.org/10.1002/jgrc.20078 